\title{
Thermal distribution analysis of rice weevil disinfestation using microwave heating treatment
}

\author{
Maliki Ibrahim ${ }^{1}$, Rosemizi Abd Rahim², Junita Mohd Nordin³ , Siti Zulaika Abdul Nyzam ${ }^{4}$, \\ Muhammad Thaqif Abdullah ${ }^{5}$ \\ ${ }^{1}$ School of Manufacturing Engineering, Universiti Malaysia Perlis, Malaysia. \\ ${ }^{2,3,4,5}$ School of Computer and Communication Engineering, Universiti Malaysia Perlis, Malaysia.
}

\begin{tabular}{l}
\hline \hline Article Info \\
\hline Article history: \\
Received Nov 09, 2018 \\
Revised Dec 10, 2018 \\
Accepted Dec 25, 2018 \\
\hline Keywords: \\
Bubuk rice \\
Dielectric properties \\
Microwave heating \\
Rice weevil \\
Thermal distribution \\
Uneven heating \\
\hline
\end{tabular}

\begin{abstract}
This paper presents an analysis of a microwave heating thermal distribution in the rice weevil disinfestation treatment. The sample of rice and rice weevil has been heated by microwave and the infrared thermal camera has been used to capture the heating distribution. The analysis of the rice and the rice weevil condition due to electromagnetic energy exposure is presented. There are three stages of the microwave heating has been taken in the analysis i.e. $10,20,30$ seconds exposure period at $100 \mathrm{~W}$ of energy. Found that the treatment of rice weevil disinfestation using microwave energy is promising in the future, but needs a lot of improvement to be studied. The beauty of using microwave energy for rice weevil disinfestation is not only the rice weevil can be killed, but even its eggs or larvae inside the rice kernel will be killed before it hatches.
\end{abstract}

Copyright $@ 2019$ Institute of Advanced Engineering and Science. All rights reserved.

\section{Corresponding Author:}

Rosemizi Abd Rahim,

School of Computer and Communication Engineering,

Universiti Malaysia Perlis, Malaysia.

Email: rosemizi@unimap.edu.my

\section{INTRODUCTION}

Rice is one of the main agriculture commodity of the Malaysian food sources. The dependence on the rice production in the country is not enough, thus the rice also imports from the neighbouring country too. To avoid the shortage of supply, the rice will be stored in large quantities in a certain period before they can be marketed. Although rice is a long lasting commodity if stored, but it still can be damaged due to the various factors such as an attack by the insect known as kutu beras or rice weevil (Sitophilus oryzae Linnaeus).

They are a few methods has been used in controlling kutu beras. The conventional method of the insecticides is used which requires rigorous control. Insecticides are sprayed directly onto the rice during unloading into the storage. Pesticides are among the most commonly used chemicals in the world, and it is dangerous to human health as well as the environment. The physical method is by manipulating the physical environment or by applying physical treatments to the insect. It includes the different types of traps (i.e.probe traps and pheromone traps), manipulation of the physical environment, mechanical impact, physical removal, abrasive and inert dusts. In biological method, the living organisms, as natural enemies are used to control the insect. They are usually species specific. To control of insect in store products, these natural enemies can be released at a one location and they will search and attack the insect.

The lifespan of an adult rice weevils is up to six or seven months. During that period, the female rice weevil capable of producing 300 to 400 eggs. The way these eggs are deviating for hatching is quite unique and very safe. The female rice weevil uses her strong mandibles to drill a hole in the rice kernel. Then she puts a single egg and seals the hole with a gelatinous fluid which they provide by their saliva. In the hot 
climax like in Malaysia, the development period for the egg to hatch is normally in twenty five days. This period is longer for cold climax. This unique hatching method of the weevil larvae causes its breeding cannot be stopped even though the disinfestation treatment process has been performed. This is a major disadvantage of conventional treatment methods. Based on that statement, now it is answered on how the rice weevil occurs in our rice storage even though there is no weevil during the rice purchasing. But after a few days or a week, a lot of weevil appears in the rice storage.

In this paper, the microwave heating treatment method as a technique to control the insect will be discussed. Commonly the people know that the microwave energy only used in preparing food. In reality, the microwave energy also has been used in the chemical field, medical field, and telecommunication industries. However, the usage of microwave energy in food industries is still the largest amount of consumer of microwave energy [1]. Food industries used this energy for thawing, cooking, tempering, drying, baking, and heating. Microwave can be divided into two categories which are domestic microwave and industrial microwave. $2450 \mathrm{MHz}$ is the frequency that is used by domestic microwave while $915 \mathrm{MHz}$ is used in industrials microwave [2].

As we all know, conventional heating is more to surface heating and absorption of heat [3]. The main point microwave energy was implemented is to increase the heating rate and reduce the time taken to get the food ready by electromagnetic energy [1]. The best part of microwave heating is processing time will be shorter compared to other device. Heat is generated by the food materials as volumetric heating. This method will lead to faster cooking and reduce processing time. Microwave energy to penetrate into the food product and produce volumetrically distributed heat sources, due to the molecular friction caused by dipole rotation polar solvent in response to a changing electric field at a rate of about 2.45 billion times per second. Figure 1 shows that the dipolar rotation due to the current microwave heating due to the change in the polarity of electromagnetic fields in the cavity over time.

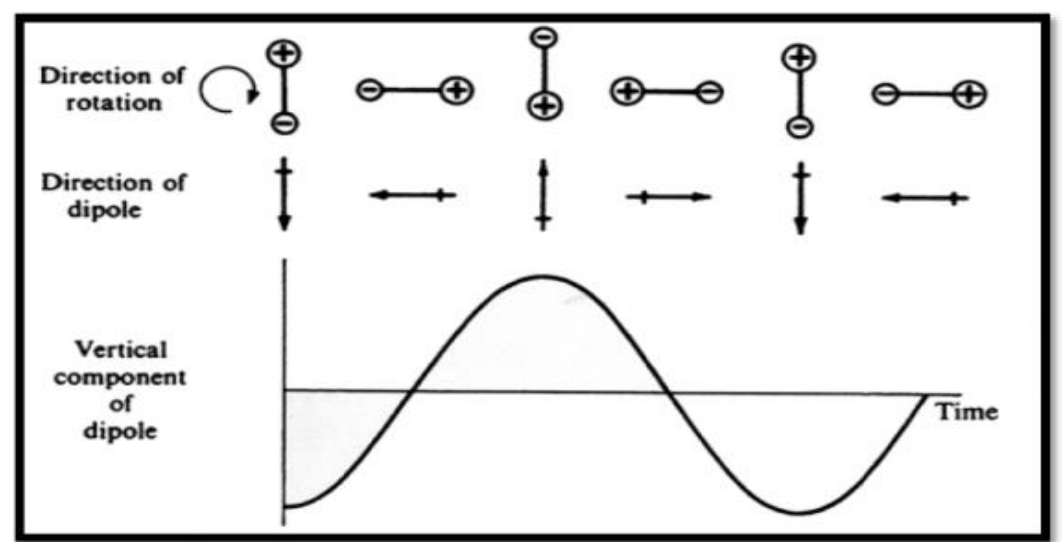

Figure 1. Variation of microwave propagation in time [3]

In article [4], they review the concept of radio frequency and microwave heating treatment to disinfest of kutu beras in rice. Researchers in [5] using Galerkin finite elements to obtained the microwave power, temperature and liquid volume fractions for microwave thawing of tylose slabs. In terms of food quality, food that prepared by microwave does not become brown and dry because the temperature inside the microwave box is room temperature [3]. The disadvantage of microwave heating is it can result, uneven heating and it will leave cold spots where it can allow bacteria to survive. The "cold" and "hot" spot can be anywhere on the food product.

A rapid and reliable method was developed in [6] and effectively locate the cold spot in model food sterilized in microwave systems. A Variable frequency heating procedures were proposed in [7] to overcome the geometry of a roughly spherical foodstuff dominating the heating pattern when heated in fixed frequency applicators. The effect of the non-uniform diffusivity as well as non-uniform electric fields on the formation of hotspots was investigated in [8]. While in [9], they studied of the uneven heating of a heated Material in a microwave oven by considering air convection and heat radiation. The uneven temperature distribution of a heated material was computed by the coupled method.

An investigation on the effect of varying the load, mesh and simulation parameters in microwave heating applications have been presented in [10]. A comprehensive analysis on the effect of shape on the 
microwave heating dynamics of food materials was studied in [11]. They analysed the effect of shape on the overall heating rate and spatial heating dynamic.

This paper will present the hotspot characterization and pattern of the microwave heating weevil in rice storage. This characterization is very important in order to study the effectiveness the application of the microwave energy in controlling the rice weevils.

\section{RESEARCH METHODOLOGY}

A microwavable jig will be developed for experimental work. The experiment will be conducted by placing the sample of rice together with the insects in the purposed jig and exposed to microwave energy. The thermal image of the material exposed to the microwave energy will be analysed.

\subsection{Rice and Rice Weevil}

Before the experiment can be conducted, the adequate sample of the rice weevil should be prepared. As already mention previously in the introduction section, there is already have a weevil egg or larvae inside the rice kernel which have been deposited by the female weevil during laying egg. In this study, we are already breeding the rice weevil by keeping it for a month. Figure 2 shows the image of the rice weevil.

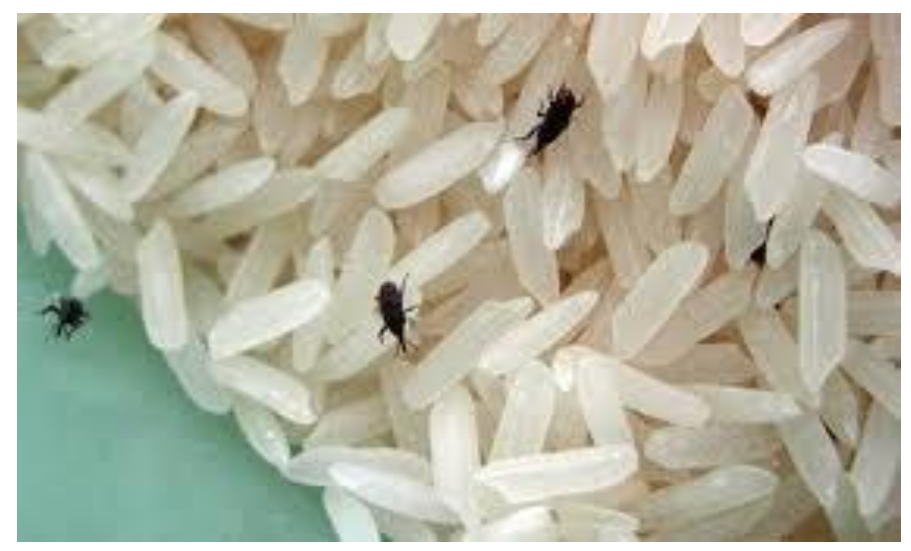

Figure 2. Rice and rice weevil

\subsection{Measuring Equipments}

In order to measure the temperature distribution hotspot heating, the infrared thermal imaging camera had been chosen, type FLIR i5 Thermal Camera. The infrared thermal camera able to detect the thermal resolution by capturing the image of the heated sample. Thus, it will give the reading of temperature and difference colour of the image which one is high temperature and which one is the low temperature.

\subsection{Experiment Setup}

A microwave heating system setup, as shown in Figure 3 has been used in our the thermal distribution characterization. The experiments were conducted by placing the sample of rice in the proposed material under test (MUT) container. Then, the rice sample moved into the proposed microwave applicator system with the selected required power and exposure time. In this experiment, 100W of power has been chosen to heat the sample. After the MUT container moving out of the microwave applicator, a thermal image of the rice sample was captured by the thermal camera. All the data were recorded in the image acquisition system. 


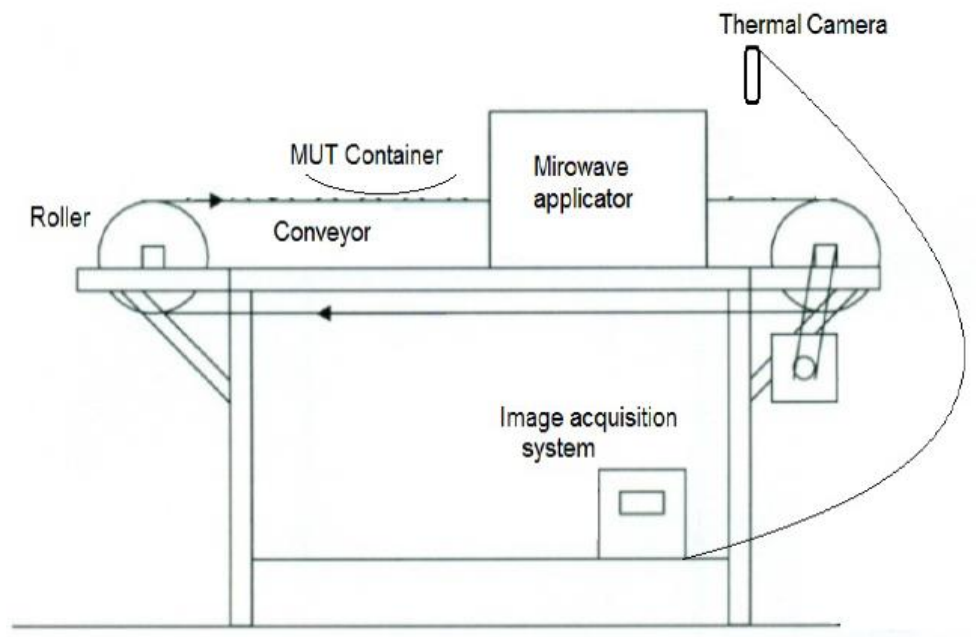

Figure 3. The experimental work setup

\section{RESULTS AND DISCUSSION}

The captured infrared thermal image distribution will be presented in this section. Infrared thermal imaging is a rapid and non-invasive procedure for mapping the temperature distribution of the sample. The colour mapping is a process that transforms the colour of an original image to target image. Image colour is transformed by algorithm and colour mapping also may be referred as an algorithm. Sometimes this method can called colour transfer. There are three main colours which are red, yellow and blue. Red colour is the highest temperature of the image while the yellow is in the middle of the temperature. Blue colour is the lowest temperature. Thus, this colour mapping range can show which part is in high temperature and which part is in the low temperature.

\subsection{Before Exposured to Microwave}

Figure 4 (a) shows the sample of rice and rice weevil before heating by microwave energy. Shown that a lot of rice weevil moving around the rice. Figure 4(b) shows that the thermal is distributed evenly.

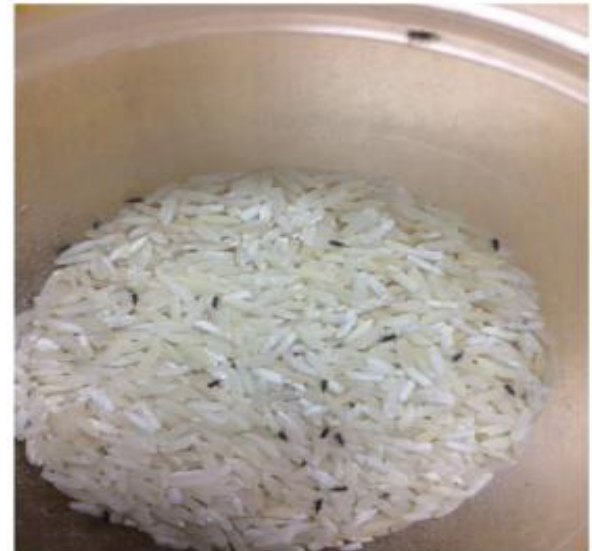

(a)

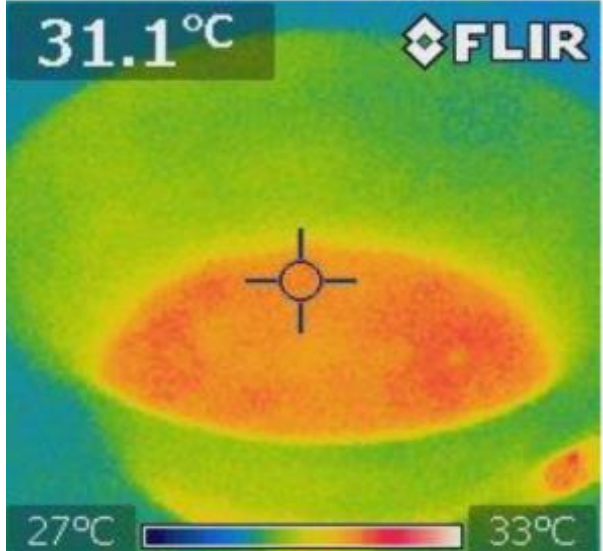

(b)

Figure 4. Before exposure to microwave

\subsection{Exposured to Microwave}

The following section will presented the result of the material after exposure to the microwave. There are there phase of the exposure in this study which is based on the duration of microwave energy exposure. 


\subsubsection{First Phase-10 seconds}

The first phase of the measurement of this experiment was to heat up the sample for 10 seconds. From the observation, found that all the rice weevils were still surviving. Figure 5 (a) shows that most the rice weevil still moving with some of the weevil were dead. Figure 5(b) shows the infrared distribution image of the sample. The temperature at the spot location was $74^{\circ} \mathrm{C}$. The highest temperature at this stage was $89^{\circ} \mathrm{C}$ and the lowest was $30^{\circ} \mathrm{C}$.

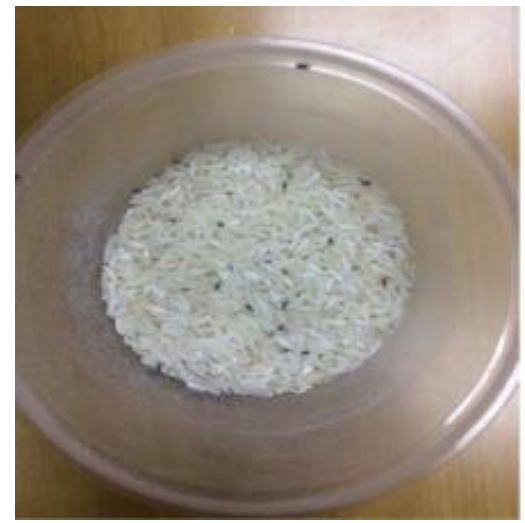

(a)

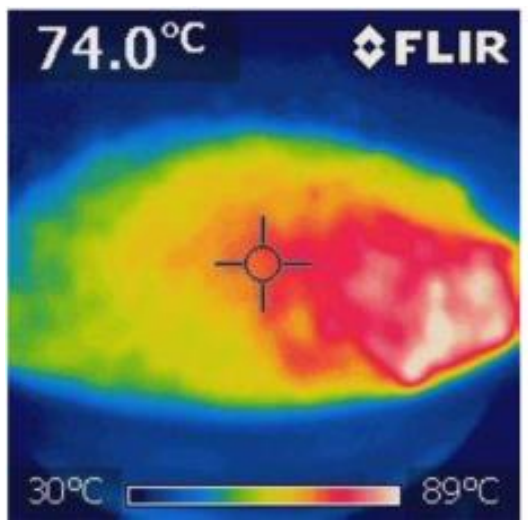

(b)

Figure 5. Exposure to microwave for 10 seconds

\subsubsection{Second Phase-20 seconds}

In this phase, the sample was exposed up to 20 seconds. Found that some of the rice weevil were dead and some of it still survives. Figure 6 (a) shows the image of rice weevil after exposed to the microwave energy for 20s while Figure 6(b) shows the infrared heating distribution image of the sample. The temperature at the spot location was $103^{\circ} \mathrm{C}$. The highest temperature of this phase was $124^{\circ} \mathrm{C}$ and the lowest was $32^{\circ} \mathrm{C}$.

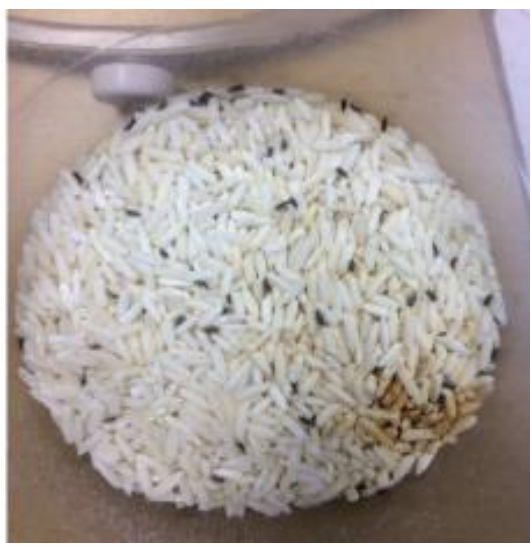

(a)

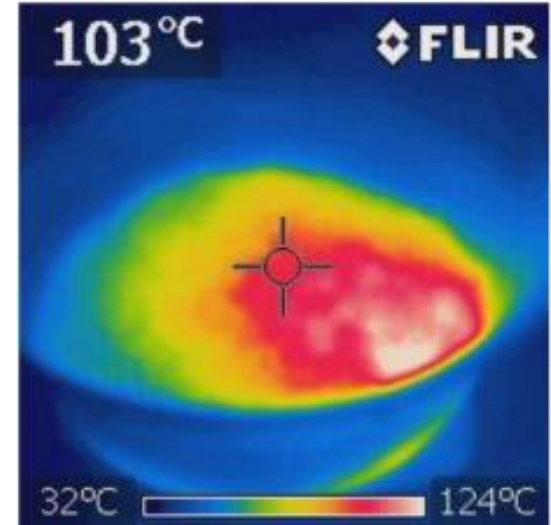

(b)

Figure 6. Exposure to microwave for 20 seconds

\subsubsection{Third Phase-30 seconds}

In this phase, the sample was exposed to the microwave energy up to 30 seconds. Found that all the rice weevils were dead. Figure 6(a) shows the image of dead rice weevils while Figure 6(b) shows the infrared distribution image of the sample. The temperature at the spot location was $103^{\circ} \mathrm{C}$. The highest temperature at this stage was $124^{\circ} \mathrm{C}$ and the lowest was $32^{\circ} \mathrm{C}$. Exposure to microwave for 30 seconds as shown in Figure 7. 


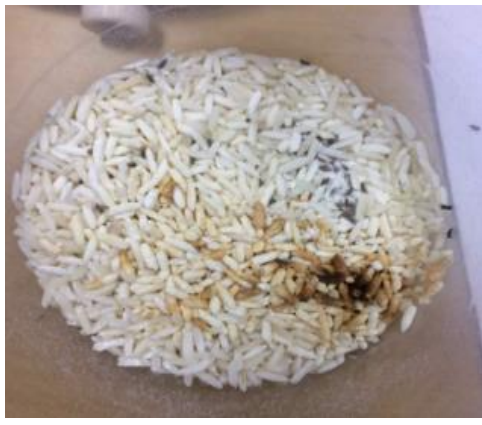

(a)

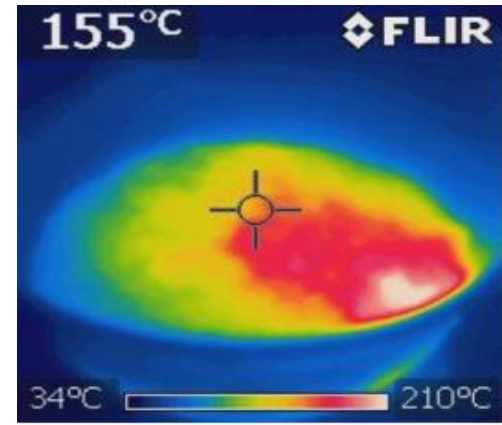

(b)

Figure 7. Exposure to microwave for 30 seconds

\section{CONCLUSION}

From the microwave heating experimental work, it is shown that the combinations of the temperature level and exposure period were able to kill all the rice weevils. It is also shown that in the first phase, which is the exposure in 10 seconds, some of the weevil are killed. Then in the second phase, it is also shown that only some of the weevil were killed. In the third stage, all the rice weevil were killed after 30s exposure. All this happens are due to the uneven or non uniform heating by the electromagnetic energy which is shown by the infrared heating distribution image. There are two factors that is important to understand the system performance and issue of non-uniform heating which are coupled electromagnetic and heat transfer modelling of microwave heating. As the conclusion, the treatment of rice weevil using microwave energy have a future, thus a lot of techniques for improvement must be studied aggressively.

\section{ACKNOWLEDGEMENTS}

The authors would like to thank the Ministry of Education (MOE), Malaysia for the funding under the Fundamental Research Grant Scheme (FRGS 9003-00597) with reference code: FRGS/1/2016/TK04/UNIMAP/02/6

\section{REFERENCES}

[1] Akarapu, R., B. Q. Li, Y. Huo, J. Tang and F. Liu. 2004. "Integrated modelling of microwave food processing and comparison with experimental Measurements". Journal of Microwave Power and Electromagnetic Energy 39(3/4): 153.

[2] Ayappa, K. G., H. T. Davis, E. A. Davis and J. Gordon. 1992. "Two dimensional finite element analysis of microwave heating". AICHE Journal 38(10): 1577-1592.

[3] Baker-Jarvis, J., R. G. Geyer, J. H. Grosvenor Jr, M. D. Janezic, C. A. Jones, B. Riddle, C. M. Weil and J. Krupka. 2002. "Dielectric characterization of low-loss materials a comparison of techniques". Dielectrics and Electrical Insulation, IEEE Transactions on 5(4): 571-577.

[4] Siti Zulaika Abdul Nyzam, Rosemizi Abd. Rahim, and Hasliza A. Rahim, "Review Article of Radio Frequency and Microwave Heating Treatment to Disinfest Kutu Beras in Malaysian Rice”, International Conference on Emerging Electronic Solution for IOT.

[5] Basak, T. and K. G. Ayappa. 1997. "Analysis of microwave thawing of slabs with effective heat capacity method". AICHE Journal 43(7): 1662-1674.

[6] Bhuwan Pandit, R., J. Tang, F. Liu and G. Mikhaylenko. 2007. "A computer vision method to locate cold spots in foods in microwave sterilization processes". Pattern Recognition 40(12): 3667-3676.

[7] Bows, J. R. 1999. "Variable frequency microwave heating of food". The Journal of Microwave Power and Electromagnetic Energy: A Publication of the International Microwave Power Institute 34(4): 227-238.

[8] Chandra D., Nusantara T., Imron M.A., "Basuki (1997) On the Formation of Hotspot in Microwa ve Heating". Differential Equations Theory, Numerics and Applications pp 245-255 Springer, Dordrecht

[9] Watanabe S, Tetsuhiro S,Hashimoto O, "Study Of Uneven Heating Of A Heated Material In A Microwave Oven Considering Air Convection And Heat Radiation", 2007 7th International Symposium on Electromagnetic Compatibility and Electromagnetic Ecology

[10] Ehlers, R. A. and R. A. Metaxas. 2007. "An investigation on the effect of varying the load, mesh and simulation parameters in microwave heating applications". The Journal of microwave power and electromagnetic energy: a publication of the International Microwave Power Institute 40(4): 251-259.

[11] Bhattacharya M, Basak T, "A comprehensive analysis on the effect of shape on the microwave heating dynamics of food materials", Innovative Food Science \& Emerging Technologies, Volume 39, February 2017, Pages 247-266. 


\section{BIOGRAPHIES OF AUTHORS}

Maliki Ibrahim received the M.Eng. (Electrical- Electronics and Telecommunications) from
Universiti Teknologi Malaysia and B.Eng. (Electric) from the Universiti Teknologi Mara,
Malaysia. Currently is a lecturer at Faculty of Manufacturing Engineering, Universiti Malaysia
Perlis (UniMAP), Malaysia. Teaches Electrical Fundamentals, Instrumentation and Integrated
Manufacturing. Intersted in Tomography, Microwave Heating and Sensors.

